\title{
Mathematical Analysis of Supply Chain Optimization focusing on Artificial Neural Network: A case study in Apparel Manufacturing Organization
}

Shibbir Ahmad ( $\square$ ahmadjerin@gmail.com )

Dhaka University of Engineering \& Technology (DUET) BIDS

Mohammad Kamruzzaman

Dhaka University of Engineering \& Technology (DUET) BIDS

\section{Research Article}

Keywords: Artificial neural network, right supplier selection, profit, supply chain optimization, cost

Posted Date: January 3rd, 2022

DOI: https://doi.org/10.21203/rs.3.rs-1173130/v1

License: (c) (1) This work is licensed under a Creative Commons Attribution 4.0 International License.

Read Full License 


\title{
Mathematical Analysis of Supply Chain Optimization focusing on Artificial Neural Network: A case study in Apparel Manufacturing Organization
}

\author{
Shibbir Ahmad * and Mohammad Kamruzzaman \\ Department of Mechanical Engineering \\ Dhaka University of Engineering \& Technology (DUET) \\ BIDS, Gazipur 1700, Bangladesh \\ ahmadjerin@gmail.com, kamruzzamn2002bd@yahoo.com
}

\begin{abstract}
In this study, implemented artificial nueral network (Ann) in apparel manufacturing organizations to optimize the supply chain converging on right supplier selection by analyzing their performance criteria.Moreover, data collected from three diffrents factory to analyze the efficiney and profit -loss status of that units. Furthermore, analyze the supplier selection criteria of three suppliers in order to select the right supplier at the real time in apparel manufacturing industry . This study shows that it can be saved $20 \%$ of the total cost.
\end{abstract}

\section{Keywords}

Artificial neural network, right supplier selection, profit, supply chain optimization, cost.

\section{Introduction}

Optimizing supply chain is very crucial for the apparel manufacturing industry since it has to be paid a plenty of cost to make the supply chain smooth from manufacturer's end and most often it cost to the overall chain members. Manufacturer has to be involved with outsourcing either due to poor supply chain performance or booking for excess order quantity. Moreover, it has additionally the jeopardy factor of goods quality product and on-time distribution cannot be achieved because of opportune monitoring since key person might not be able to provide adequate time into outsourcing factory and hence that incur further charge for airing (shipment through air freight) the goods and/or there is a probability to get claim due to poor quality products. So, in order to procure the goal of supply chain optimization, company has to ameliorate productivity, quality and distribution (PQD). To do so, factory has to ascertain that there is a good team work amongst the employees which ascertain the company is going forward by providing opportune guidelines and congruous training to its lower caliber and mid-level management. Furthermore, conducting perpetual training to workers for their adeptness development which additionally integrate value to optimization for supply chain. On the other hand, both Quality Management System (QMS)and Requisites for Quality System (RQS) are responsible to be committed to facilitate accommodations to the company to acquire the optimum result for the manufacturing unit. Overall, it can be conserved up to $30 \%$ of the total cost. In this research, developing a mathematical model to make the supply chain optimized will be the major focus.

\section{Literature Review}

While most extreme aim of western nations is to diminish engenderment costs. Then again, they will undoubtedly follow through on a significant expense for incapable coordination's when in any event, passing on the merchandise from the nearby producer in China or abroad that is associated with moderately higher coordination's costs which deteriorating item quality. Larger part of the Bangladeshi pieces of clothing producing associations source textures and trims (fundamentals needed for attire fabricating) from abroad, are the most tedious matter just as carrying materials into the distribution center is lavish. One of the center hindrances for the smooth production network is because of procurement materials from abroad for the Bangladeshi attire fabricating industry. Traditionally it requires 60 days lead time to show up materials from in a peregrine nation like China to Bangladesh later than setting requests 
and plant get just under 30 days lead time to inducing and transportation the items to the end clients. In the interim, separating right provider at the ideal opportunity is the critical variable to make the smooth inventory network and accomplish advanced chain execution. Thus, the centrality of the store network improvement through exact provider winnow to articles of clothing processing plant in our region is irreplaceable. Organization of fake perspicacity in provider separate can improve the strategy for action predicated costing [1]. Besides, separation is expectedly used in the inclination setting to condense the genuine capacity to track down an ideal arrangement Inclination predicated approach is likely to have a numerical articulation of the goal work. At the point when such numerical articulation can't be gotten, there is an objective to use an assessment method to initiate the arrangement technique. The assessed slopes bearing aides the inquiry interaction to peregrinate starting with one potential arrangement then onto the next in an iterative plan in a cycle called stochastic estimation [2]. Various carries out executed in provider winnow, for example, group investigation, factual techniques, information improvement examination, case predicated thinking frameworks, choice emotionally supportive networks, absolute expense of proprietorship models, numerical programming, etc [3][4][5][6]. The unique focus for the ANN practice set must be surrendered to ignore fitting estimation that clearly influences the prescient accuracy coming about out of ANN. Plan of tests (DOE) can be cumulated with ANN to conquer over-fitting difficulty [7]. A few recreation methods are as needs be executed to evaluate the assortments setups of the framework to be advanced. Such sort of improvement is called as recreation streamlining in Activity Exploration (OR) writing [8]. Then again, one more strategy used to improve the stochastic objective capacities are called direct hunt techniques, since the irregularity is dealt with straight by upgrading stochastic capacities [9]. Comprehensive unique activities of a kenned network structure with an activity irregularity. Reenactment displaying can be accustomed to evaluate SC execution for an insight design. In the second a moiety of the twentieth century, advancement has turned into a far and wide strategy, in regions, for example, synthetic and cycle designing, coordination's, financial matters, and SC plan [10]. Quality control (QC) framework is regularly an issue and the use may be raised because of high paces of renouncement, repackaging, scrap and improve, and lost deals due to out-of-stocks and slow turns [11]. Effective stock chains should be adaptable and friendly to the changing elements in the rialto, in assembling and innovation, and in buyer possibilities. This is withal genuine for general wellbeing supply chains, which should react and conform to dynamic conditions. Store network advancement is an ascendant, commonsense carry out that can enhance execution now and stand firm on foothold of the inventory chains for what's to come. However reenactment is quite possibly the most prosperous gear for breaking down production network processes [12]. Moreover, Fake Neural Organizations (ANNs) to be one more solid strategy to assessed subjective smooth capacities and can be tweaked using stochastic replication esteems [13]. As indicated by Papageorgiou (2009), current modern ventures comprise of various tasks, destinations and offices, which can be situated in various nations, districts, or parts of the world. The creator further contends that various exercises of SCs including arranging, participation and coordination, and responsiveness to client requests should be considered to determine adequacy, seriousness, supportability, and amplification of SCs. Inventory network the executives (SCM) includes kineticism of material and facilities from upstream to downstream activities of SCs. In the present ecumenical and serious climate, SCM and dynamic interaction emerges both from key and functional stances [14] . Any "plan" of a SC traditionally includes tradeoffs between clashing targets and, according to the supportability point of view, between monetary, ecological and pleasant goals. Therefore, reasonable turn of events and multi-rules improvement in SC network configuration is a captivating point deserving of study [15] . Multi-objective streamlining is generally applied to various dynamic pickles and the execution of improvement in navigation has outwardly seen developing interest as of late [16]. Increased globalization and furious rivalry are pressuring organizations to be more productive and adaptable. Organizations should match injuctively approving financial targets and simultaneously working in a maintainable way just as they should address customer issues [17]. The objective of SCM is to methodicallly coordinate providers, producers and customers for merchandise and facilities to be made and appropriated perfectly located, exact time, and in the perfect sum, while at the same time learning greatest SC execution [18]. Practical advancement of SCs is a critical piece of any business and proficient SCs are basic for great items and for on-time appropriation. Therefore, working SCs in a feasible way is an involute undertaking, whose involution relies upon the quantity of echelons, materials, and facilities inside SCs [19] . As indicated by Papageorgiou (2009), a wide range of plans and approaches of numerical models are used in SC advancement. The most pervasive methodologies are numerical programming, recreation, or a combination of the two techniques. Their application relies upon the issue to be settled. Numerical programming and numerical demonstrating is ordinarily used for advancement of choices that include nascent setups, with mixed part of elements and construction of activities, for example, SC network structure plan. A few survey papers are distributed in the last two decenniums that address various parts of SCs, e.g., SC the executives, green parts of SCs [21], ecumenical SC models and plan [22] , and multi-objective advancement [23] .Whereas reenactment models consider SC network configuration can be separated into two plan types, specifically, open circle organizations and shut circle networks where the reversal stream is joined [24]. In this paper, we will be 
fostered a strategy for fitting provider winnow by executing AHP Model just as foster an outcome situated method for improving inventory network enhancement in attire fabricating associations.

\section{Proposed supplier selection criteria}

The supplier selection criteria demonstrated in the table 1 to 3 respectively for diverse apparel manufacturing industry. The best supplier selected based on the highest average scoring from the various criteria. In this research, it took into consideration several principles for instances quality, capacity, service, cost, delivery, sustainability, csr and ethics in order to select best and right supplier. The best supplier selected S3, S5, S1 for the manufacturing unit 1 to 3 respectively.

Table 1. Supplier criteria criteria of PU1

\begin{tabular}{c|c}
\hline Supplier & Average Rating \\
\hline S1 & 0.64125 \\
\hline S2 & 0.65625 \\
\hline S3 & 0.66625 \\
\hline S4 & 0.65875 \\
\hline S5 & 0.6275 \\
\hline
\end{tabular}

The data collected from three different apparel manufacturing company and have been implemented though software like R Studio, Python and Minitab and got different outcomes and can take decision to which supplier can select scientifically and manually from their criteria.

Table 2. Supplier criteria criteria of PU2

\begin{tabular}{c|c}
\hline Supplier & Average Rating \\
\hline S1 & 0.62125 \\
\hline S2 & 0.60125 \\
\hline S3 & 0.5925 \\
\hline S4 & 0.60125 \\
\hline S5 & 0.6425 \\
\hline
\end{tabular}

In addition, data validation analysis has been done through python. Input treats as expected criteria of the supplier selection and output deemed as the currently delivering performance criteria. Data analysis showed that expected input and output could be attainable with the respective weights provided by python code.

Table 3. Supplier criteria criteria of PU3

\begin{tabular}{c|c}
\hline Supplier & Average Rating \\
\hline S1 & 0.68375 \\
\hline S2 & 0.6225 \\
\hline S3 & 0.625 \\
\hline S4 & 0.6325 \\
\hline S5 & 0.61125 \\
\hline
\end{tabular}




\subsection{Artificial neural network (ANN)}

$$
\begin{aligned}
& \text { net }_{h 1}=w_{1}^{*} i_{2}+w_{2}^{*} i_{2}+b_{1}^{* 1} \\
& \text { out } t_{h 1}=\frac{1}{1+e^{-n e t_{h 1}}} \\
& \text { net } t_{o 1}=w_{5}{ }^{*} \text { out }_{h 1}+w_{6}{ }^{*} \text { out }_{h 2}+b_{2}{ }^{* 1} \\
& \text { out } t_{o 1}=\frac{1}{1+e^{-n e t_{o 1}}} \\
& \left.E_{\text {total }}=\sum \frac{1}{2} \text { (t arg et-output }\right)^{2} \\
& E_{01}=\sum \frac{1}{2}\left(\text { targ et } t_{01}-\text { out }_{t_{1}}\right)^{2} \\
& E_{02}=\sum \frac{1}{2}(\text { t arg etor-outo2 })^{2} \\
& E_{\text {total }}=E_{01}+E_{02} \\
& \frac{\partial E_{\text {total }}}{\partial \mathrm{Dut}}=-(\text { target01 - outo1 }) \\
& \frac{\partial o u t_{01}}{\partial \text { net }_{01}}=\text { out }_{o 1}{ }^{-(1-\text { outor })} \\
& \text { net }_{01}=W_{5}{ }^{*} \text { out }_{h 1}+W_{6}{ }^{*} \text { out }_{h 2}+b_{2}{ }^{* 1} \\
& \frac{\partial E_{\text {total }}}{\partial W_{5}}=-\left(\operatorname{target}_{01}-\text { out }_{01}\right)^{*} \text { out }_{01}\left(1-\text { out }_{01}\right)^{*} \text { out } t_{\text {h1 }} \\
& \delta_{01}=-\left(\text { target }_{01}-\text { out }_{01}\right)^{*} \text { out }_{01}\left(1-\text { out }_{01}\right) \\
& \frac{\partial E_{\text {totral }}}{\partial W_{5}}=\delta_{o 1^{\text {outh } 1}} \\
& \frac{\partial E_{\text {totral }}}{\partial W_{5}}=-\delta_{o 1^{\text {out } h 1}} \\
& \boldsymbol{w}_{5}^{+}=\boldsymbol{w}_{5}-\eta * \frac{\partial E_{\text {total }}}{\partial_{w 5}}
\end{aligned}
$$

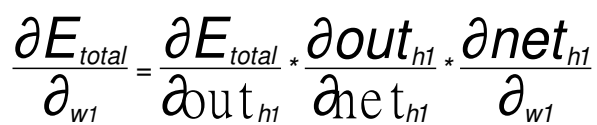

$$
\begin{aligned}
& \frac{\partial E_{\text {total }}}{\partial \text { out }_{h 1}}=\frac{\partial E_{01}}{\partial u t_{h 1}} * \frac{\partial E_{o 2}}{\partial u t_{h 1}} \\
& E_{\text {total }}=E_{01}+E_{02} \\
& \text { net }_{01}=W_{5}{ }^{*} \text { out }_{h 1}+W_{6}{ }^{*} \text { out }_{h 2}+b_{2}{ }^{* 1}
\end{aligned}
$$




\section{$\frac{\text { anet }_{o 1}}{\text { ovut }_{h 1}}=w_{5}$}

$o u t_{h 1}=\frac{1}{1+e^{n e t_{h 1}}}$

$\frac{\partial_{u t_{h 1}}}{\partial_{e_{h 1}}}=O u t_{h 1}\left(1-o u t_{h 1}\right)$

$\frac{\partial E_{\text {total }}}{\partial_{w 1}}=i_{1}$

$\frac{\partial E_{\text {total }}}{\partial_{w 1}}=\left(\sum_{0} \delta_{0}{ }^{*} W_{h o}\right)^{*}$ out $_{h 1}\left(1-\text { out }_{h 1}\right)^{*} i_{1}$

$\frac{\partial E_{\text {total }}}{\partial_{w 1}}=\delta_{h 1^{i 1}}$

$w_{1}^{+}=w_{1}-\eta * \frac{\alpha_{t o t a l}}{\partial_{v_{1}}}$

\subsection{Mathematical analysis and calculation}

Data has been analyzed through artificial neural network

Which showed in figure 1. The analysis has been performed with three parameters i.e input data, hidden data and output data. Both forward and backward propagation has taken into consideration for getting real outcome. A mathematical analysis has been done in three production unit (PU) and found net value of error. Table 1 depicted that calculated error found 0.0014 for PU 1 which is very closed to zero and hence supply chain optimization improved into acceptable level for the apparel manufacturing organization. Net value of outh1 and outh 20.86956 and 0.99552 respectively. At the same time, value of Outo1 and Outo2 is 0.05470 and 0.99985 correspondingly.

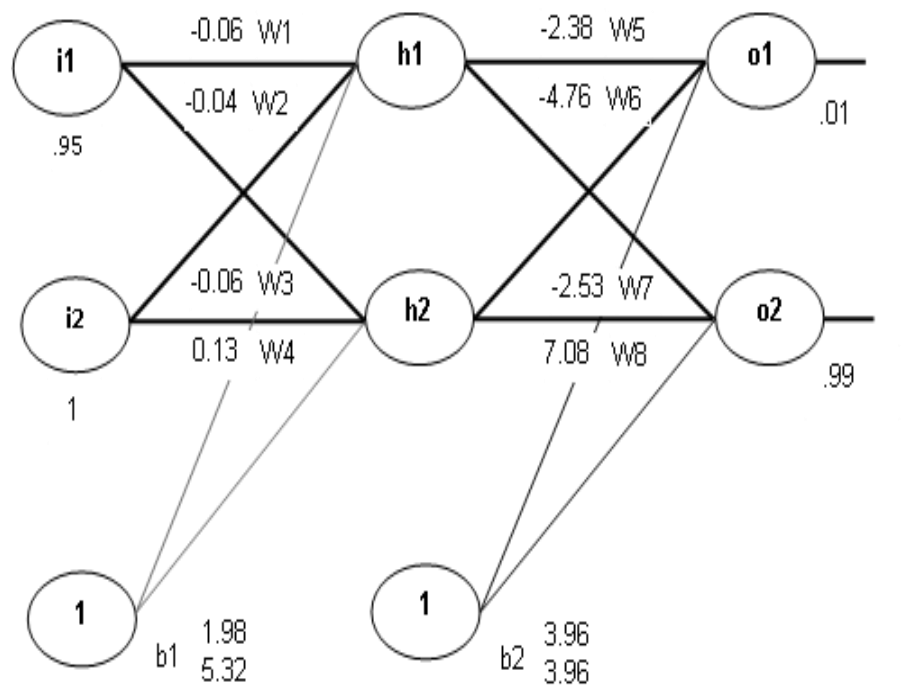

Figure 1. Artificial neural network analysis 
Table 4 portrayed that calculated error found 0.0014 for PU 1 which is very closed to zero and hence supply chain optimization ameliorated into acceptable level for the apparel manufacturing organization.

Table 4. Calculated outcomes of PU1

\begin{tabular}{c|c}
\hline Parameters & Calculated outcome \\
\hline Net $_{\mathrm{h} 1}$ & 1.88458 \\
\hline $\mathrm{Net}_{\mathrm{h} 2}$ & 5.39414 \\
\hline Out $_{\mathrm{h} 1}$ & 0.86956 \\
\hline Out $_{\mathrm{h}}$ & 0.99552 \\
\hline $\mathrm{Net}_{\mathrm{o} 1}$ & 2.84824 \\
\hline $\mathrm{Net}_{\mathrm{o} 2}$ & 8.80828 \\
\hline Out $_{\mathrm{o} 1}$ & 0.05470 \\
\hline Out $_{\mathrm{o} 2}$ & 0.99985 \\
\hline $\mathrm{E}_{\mathrm{o} 1}$ & 0.00099 \\
\hline $\mathrm{E}_{\mathrm{o} 2}$ & 0.00048 \\
\hline $\mathrm{E}_{\mathrm{total}}$ & 0.0014 \\
\hline
\end{tabular}

Table 5 portrayed that calculated error found 0.0001 for PU 2 which is very closed to zero and hence supply chain optimization improved into acceptable level for the apparel manufacturing organization.

Table 5. Calculated outcomes of PU2

\begin{tabular}{c|c}
\hline Parameters & Calculated outcome \\
\hline Net $_{\mathrm{h} 1}$ & 1.9525 \\
\hline Net $_{\mathrm{h} 2}$ & 7.3528 \\
\hline Out $_{\mathrm{h} 1}$ & 0.7825 \\
\hline Out $_{\mathrm{h} 2}$ & 0.8702 \\
\hline Net $_{\mathrm{l}}$ & -3.7825 \\
\hline Net $_{\mathrm{o} 2}$ & 8.5088 \\
\hline Out $_{\mathrm{o}}$ & 0.0372 \\
\hline Out $_{\mathrm{o} 2}$ & 0.9925 \\
\hline Eo1 & 0.0009 \\
\hline Eo2 & 0.0002 \\
\hline Etotal & 0.0001 \\
\hline
\end{tabular}

Table 6 depicted that calculated error found 0.0000 for PU 3 which is very closed to zero and hence supply chain optimization ameliorated into acceptable level for the apparel manufacturing organization. 
Table 6. Calculated outcomes of PU3

\begin{tabular}{|c|c|}
\hline Parameters & Calculated outcome \\
\hline $\mathrm{Net}_{\mathrm{h} 1}$ & 2.0525 \\
\hline $\mathrm{Net}_{\mathrm{h} 2}$ & 6.9522 \\
\hline Out $_{\mathrm{h} 1}$ & 0.7921 \\
\hline $\mathrm{Out}_{\mathrm{h} 2}$ & 0.8301 \\
\hline $\mathrm{Net}_{01}$ & -4.0130 \\
\hline $\mathrm{Net}_{02}$ & 9.0011 \\
\hline Out $_{\text {o1 }}$ & 0.0401 \\
\hline Out $_{02}$ & 0.9901 \\
\hline Eo1 & 0.0009 \\
\hline Eo2 & 0.0001 \\
\hline Etotal & 0.0000 \\
\hline
\end{tabular}

\subsection{Software validity}

Figure 1 depicted the analysis of the supplier selection considering data collection from manufacturing unit 1 where 28579 steps have taken by R studio to validate the weights in ANN and also error found 0.00025 during the analysis which is very negligible.

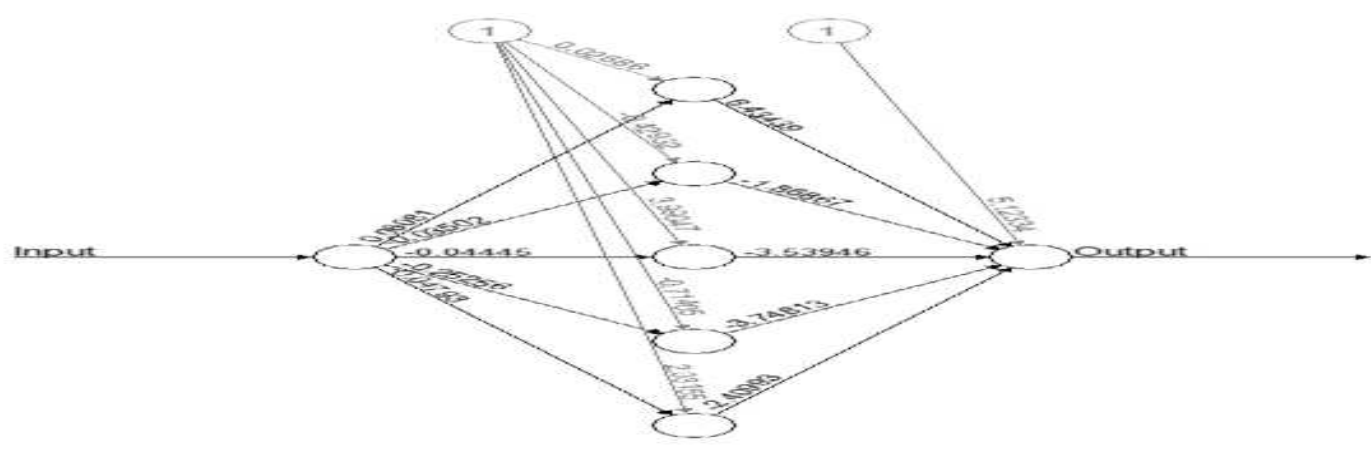

Figure 2. Neural network developed through R studio of PU1.

Similarly figure 2, 3, 4 and 5 portrayed the supplier selection validation through R software and found steps taken 3086, 4282, 8182 and 12673 as well as errors rate $0.000618,0.002863,0.00095,0.000593$ respectively for the manufacturing unit $2,3,4$, and 5 . 


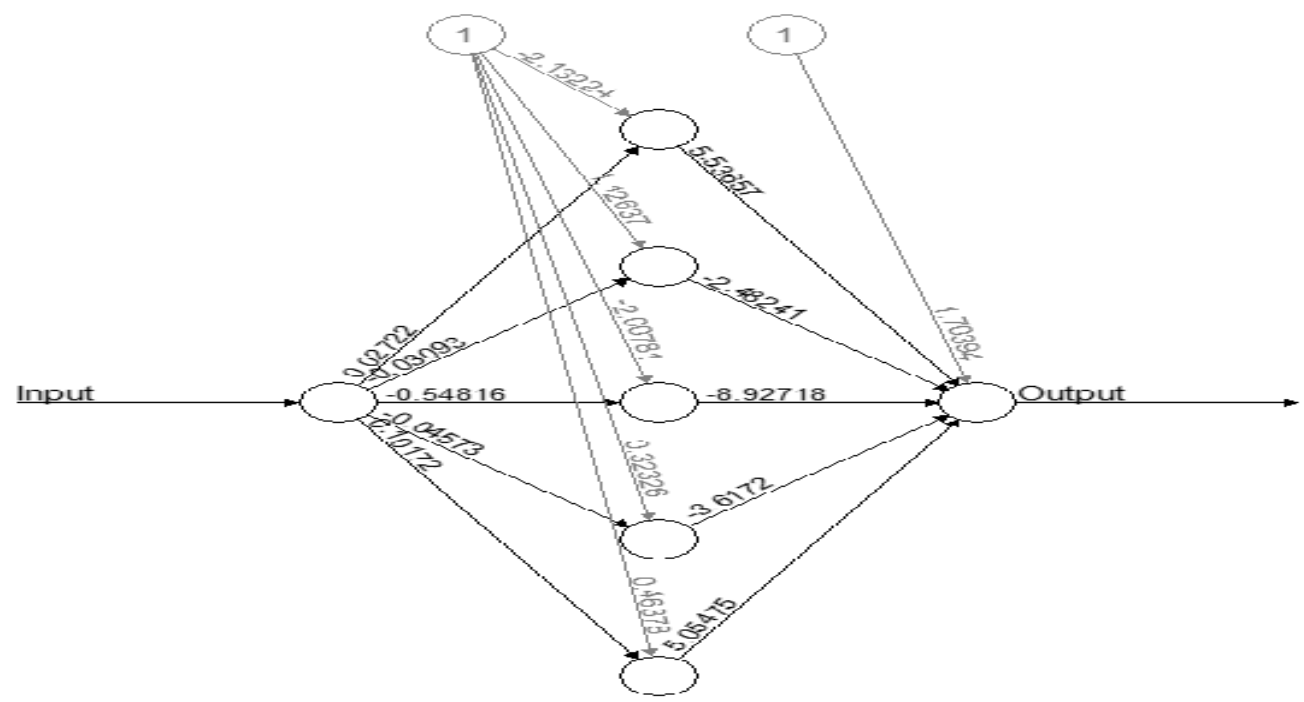

Figure. 3. Coded ANN of PU2

Similarly figure 2, 3, 4 and 5 portrayed the supplier selection validation through $\mathrm{R}$ software and found steps taken $3086,4282,8182$ and 12673 as well as errors rate $0.000618,0.002863,0.00095,0.000593$ respectively for the manufacturing unit $2,3,4$, and 5 .

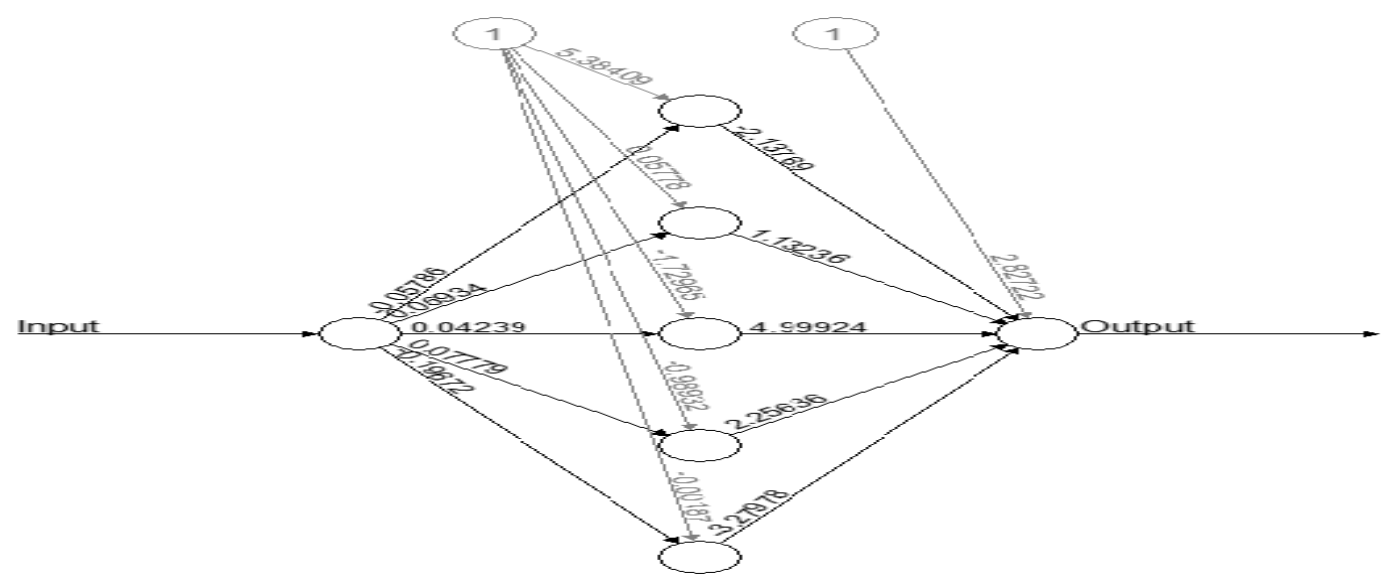

Figure. 4. Coded ANN of PU3

\section{Results and Discussions}

In this research, the data analysis has been conducted for five renowned apparel manufacturing factories in Bangladesh. Efficiency status of these factories are really worsening in the course of production gap. 


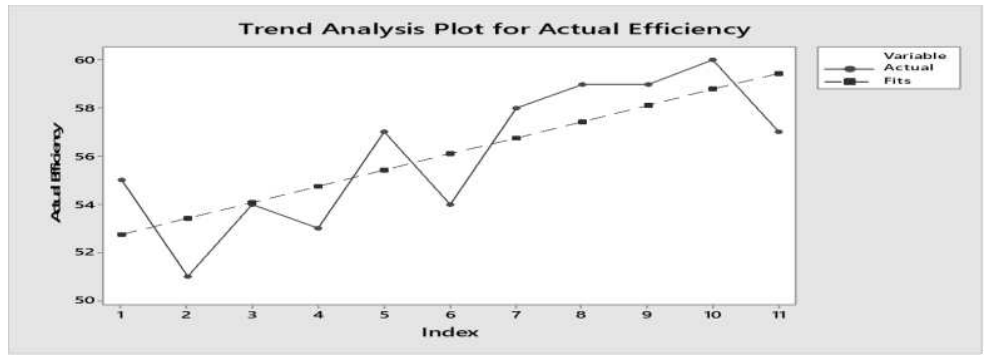

Figure. 5. Efficiency trend of PU1.

This gap happened due to delay receiving of raw materials. The delay receiving of the raw materials due to the inappropriate supplier selection focusing on conventional method.

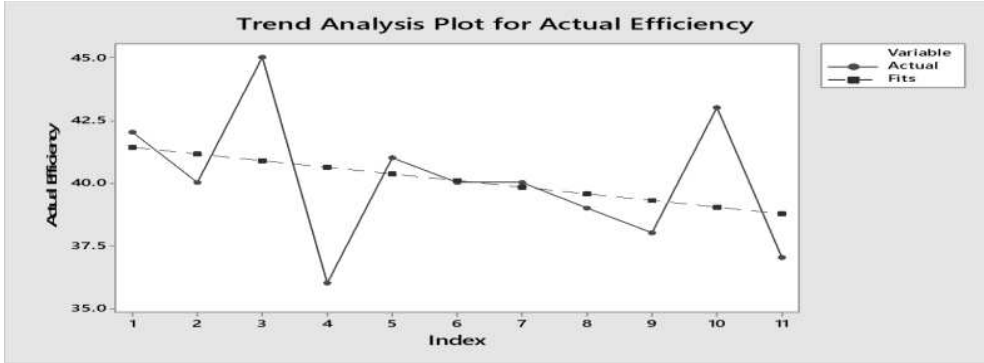

Figure.6. Efficiency trend of PU2.

This gap happened due to delay receiving of raw materials. The delay receiving of the raw materials due to the inappropriate supplier selection focusing on conventional method.

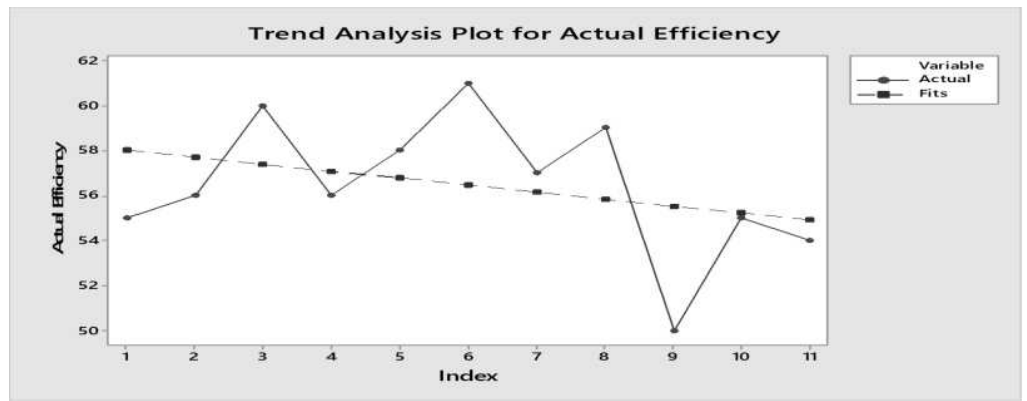

Figure. 7. Efficiency trend of PU3.

Hence, the profitability of the company become down. Therefore, the optimization of the supply chain in apparel manufacturing industry is very crucial phenomenon. The data analysis has been done through Minitab software. 


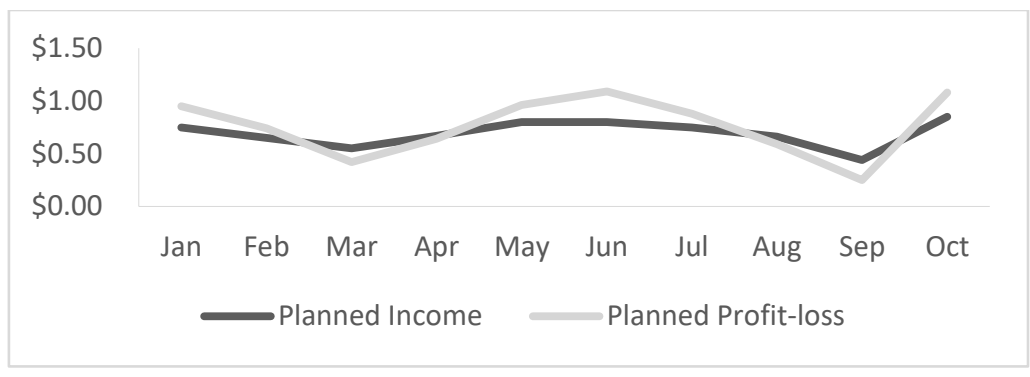

Figure. 8. Profit and loss analysis of PU1.

The planned efficiency of the PU2 is the $65 \%$ where figure 6 showed that the scenarios of the efficiency level of that factory for the last eleven months came between $53 \%$ to $58 \%$ where almost $8 \%$ of the efficiency loss for this factory. Similarly, it has been depicted from figure 7 the efficiency status of the PU3. It showed that planned target efficiency was $58 \%$ for the manufacturing unit whereas their achievement was $45 \%$ to $48 \%$. As a result, the factory lost $8 \%$ to $12 \%$ efficiency since the materials had not received in the timely manner which is the results of poor supplier selection.

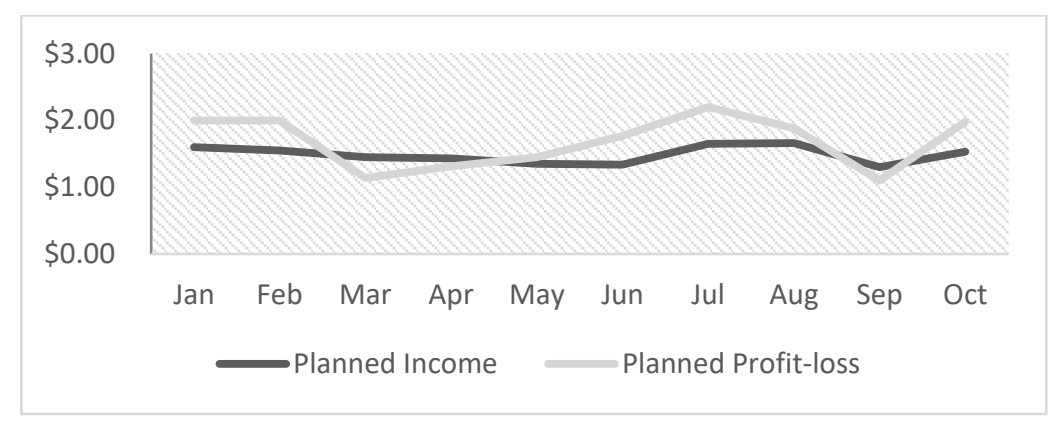

Figure. 9. Profit and loss analysis of PU2

Resulting in, they had to agony for paying to the workers in a timely manner. Irregular payments lead to unrest at the factory leads to cancellation of the orders as well as at the end of the hour factory might be at the risk situation to survive in the market. In this context, selection of the right supplier at real time by the proper method is the important event. From figure 8, 9, and 10 demonstrated the planned income versus planned profit-loss analysis for manufacturing unit 1,2 and 3 respectively. The company's profit margin is very closed to the planned target.

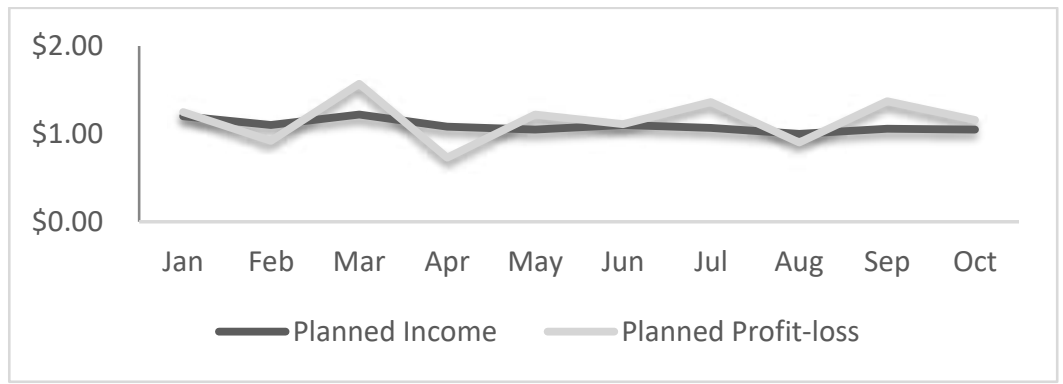

Figure. 10. Profit and loss analysis of PU3 


\section{Conclusions}

Supply chain optimization is the crucial point for apparel manufacturing industry as labor cost has been in increasing day by day quickly which lessen profit margin. In this research, we have been analyzed data to optimize supply chain in the selected apparel manufacturing organization. This study showed that $15 \%$ efficiency has been improved through implementation of optimization strategy. The cost of air freight and imposing discount on goods for the delay shipment has been reduced to very negligible amounts which was almost 15 to $20 \%$ of the total cost. Analyzing supply chain optimization in at least ten garments manufacturing industry to get the authentic scenario of the chain optimization and the cost of delaying shipment would be the future research recommendation.

\section{Nomenclature}

$E$ : (Effective) work potential

$E_{0}$ : Exergy

$E_{00}$ : Energy of a system

$\mathrm{K}:$ : Kelvin temperature scale

S: Entropy

$\mathrm{T}:$ Temperature or Celsius temperature scale

$\mathrm{W}$ : Effective work

\section{References}

[1] ROODHOOFT, F. AND KONINGS, J. (1996) 'Vendor selection and evaluation an activity-based costing approach', European journal of operation research, Vol. 96, pp.97-102.

[2] H.Robbins et al (1951), A Stochastic Approximation method, Ann. Math. Statist. 22(3): 400-407 (September, 1951). DOI: $10.1214 / \mathrm{aoms} / 1177729586$.

[3] DE BOER, L., LABRO, E. AND MORLACCHI, P. (2001) ‘A review of methods supporting supplier selection', European Journal of Purchasing Supply Management, Vol. 7, pp.75-89.

[4] TALLURI, S. (2002) 'A buyer seller game model for selection and negotiation of purchasing bids',European Journal of Operation Research, Vol. 143, pp.171-180.

[5] CHOY, K.L., LEE, W.B. AND LO, V. (2003) 'Design of a case based intelligent supplier relationship management system-the integration of supplier rating system and product coding system', Expert System Application, Vol. 25, pp.87-100.

[6] ZHU, J. (2004) 'A buyer seller game model for selection and negotiation of purchasing bids:an extensions and new models', European Journal of Operation Research,Vol. 134, pp.150-156.

[7] ALAM, F. M., MCNAUGHT, K. R. \& RINGROSE, T. J. (2004) A comparison of experimental designs in the development of a neural network simulation metamodel. Simulation Modelling Practice and Theory, 12, 559-578.

[ 8] TEKIN, E. \& SABUNCUOGLU, I. (2004) Simulation optimization: A comprehensive review on theoryand applications. IIE Transactions, 36, 1067-1081.

[9] TERZI, S. \& CAVALIERI, S. (2004) Simulation in the supply chain context : a survey computers in industry ,53, 3-16.

[10] Sahinidis, N. V. (2004). Optimization under Uncertainty: State-of-the-Art and Opportunities.Computers \& Chemical Engineering, 28(6-7), pp.971-983.

[11] NASSIMBENI GUIDO, SARTOR MARCO. (2006) Sourcing in China, Palgrave.

[12] BEYER, H. G. \& SENDHOFF, B. (2007) Robust optimization-A comprehensive survey. Computer methods in applied mechanics and engineering, 196, 3190-3218.

[13] HAYKIN, S. (2008) Neural networks: a comprehensive foundation, Prentice Hall.

[14] Papageorgiou, L. G. (2009). Supply Chain Optimization for the Process Industries: Advances and Opportunities. Computers \& Chemical Engineering, 33(12), pp. 1931-1938.

[15] Wang, F., Lai, X., \& Shi, N. (2011). A Multi-Objective Optimization for Green Supply Chain Network Design.Decision Support Systems, 51(2), pp. 262269.

[16] Jamshidi, R., Fatemi Ghomi, S. M. T., \& Karimi, B. (2012). Multi-Objective Green Supply Chain Optimization with a New Hybrid Memetic Algorithm Using the Taguchi Method. . Scientia Iranica, 19(6), pp.1876-1886.

[17] Barbosa-Póvoa, A. P. (2012). Progresses and Challenges in Process Industry Supply Chains Optimization. Current Opinion in Chemical Engineering, 1(4), pp. 446-452. 
[18 ] Ruiz-Femenia, R., Guillén-Gosálbez, G., Jiménez, L., \& Caballero, J. A. (2013). Multi-Objective Optimization of Environmentally Conscious Chemical Supply Chains under DemandUncertainty.Chemical Engineering Science, 95,pp. 1-11.

[19] Barbosa-Póvoa, A. P. (2014). Process Supply Chains Management Â $€$ “ Where Are We? Where to Go Next? Frontiers in Energy Research, 2.

[20] Croom, S., Romano, P., \& Giannakis, M. (2000). Supply Chain Management: An AnalyticalFramework for Critical Literature Review. European Journal of Purchasing \& Supply Management, 6(1), pp. 67-83.

[21] Srivastava, S. K. (2007). Green Supply-Chain Management: A State-of-the-Art Literature Review. International Journal of Management Reviews, 9(1), pp.53-80.

[22] Meixell, M. J., \& Gargeya, V. B. (2005). Global Supply Chain Design: A Literature Review and Critique. Transportation Research Part E: Logistics and Transportation Review,41(6), pp. 531-550.

[23] Trisna, T., Marimin, M., Arkeman, Y., \& Sunarti, T. C. (2016). Multi-Objective Optimization for Supply Chain Management Problem: A Literature Review. Decision Science Letters,pp. 283-316.

[24] Nurjanni, K. P., Carvalho, M. S., \& Costa, L. (2017). Green Supply Chain Design: A Mathematical Modeling Approach Based on a Multi-Objective Optimization Model.. International Journal of Production Economics, 183, pp. 421-432. 


\section{Supplementary Files}

This is a list of supplementary files associated with this preprint. Click to download.

- supplychainShibbirAhmad.docx 